\title{
O lock-in estratégico em relacionamentos inter- organizacionais: o caso da Dataprev
}

\author{
Strategic Lock-in in Inter-organizational Relationships: The case of Dataprev
}

\author{
Joao Paulo Vieira Tinoco ${ }^{1}$ \\ T. Diana L. van Aduard de Macedo-Soares, Ph. $D^{2}$
}

\begin{abstract}
Resumo
Alianças e redes estratégicas ganharam destaque na administração, sendo vistas como um meio para as empresas adquirirem recursos que Ihes proporcionem uma vantagem competitiva sustentável. Neste ambiente, a competição não ocorre apenas entre empresas diferentes, mas também entre as diferentes redes de alianças estratégicas. Entretanto, o compromisso com a própria rede também pode trazer problemas para uma empresa. Isto se dá quando os relacionamentos causam restrições a um processo de mudança e impedem a empresa de fazer negócios, o que mantém a empresa focal presa a uma situação denominada 'bck-in'. Neste artigo, descreve-se o caso da Dataprev, uma empresa pública de serviços de tecnobgia da informação, que toma a decisão de mudar sua estratégia em relação à sua parceria com um fornecedor. A nova orientação estratégica não é implementada no tempo desejado, em virtude de este relacionamento ter criado uma situação de lock-in. A pesquisa foi realizada por meio da análise de documentos e entrevistas com gerentes da empresa nos meses de maio e junho de 2007. Devido ao lock-in, ficou evidenciada a dificuldade de implementação da nova estratégia, o que fornece lições para empresas que se encontram neste tipo de situação.
\end{abstract}

Palavras-chave: estratégia; alianças; redes estratégicas; lock-in.

\section{Abstract}

Alliances and strategic networks gained prominence in the field of business administration, being viewed as a means for acquiring resources that provide a sustainable competitive advantage. In this context, competition occurs between groups that form a strategic network. However, commitment to the network can also create problems for a company. This happens when the company ceases to do business because the relationship causes restrictions to the change process, maintaining the firm in what is called a lock-in situation. This article describes the case of Dataprev, a state owned company specialized in information technology services, which decides to change its strategy with respect to its partnership with a supplier, but, because this relationship has created a bck-in situation, it cannot implement the new strategy with in the necessary time-frame. The research was conducted by way of a documental investigation as well as interviews with company managers from May to June 2007. While making evident the difficulty to implement the new strategy due to this bck-in situation, it provided insights lessons for companies in similar situations.

Keywords: strategy; alliances, strategic networks; lock-in.

\footnotetext{
${ }^{1}$ Doutorando em Administração de Empresas da Pontifícia Universidade Católica - PUC-RJ. Professor na PUC/RJ. Endereço: R Gomes Carneiro, 141 / CO2 I panema - Rio de Janeiro/RJ - Brasil - CEP: 22071110. Email: jptinoco@gmail.com

2 Ph.D. (Doutor pela University of Montreal, Canadá). Vínculo Institucional: Professor Associado, PUC-Rio/IAG - Dept. de Administraçao de Empresas. Endereço:Rua Marquês de São Vicente, 225, 22453-900 Rio de Janeiro, RJ. website: www.strategy-research.com Email: redes@strategy-research.com

Artigo submetido em janeiro de 2008 e aceito em fevereiro de 2008
} 


\section{Introdução}

À medida que os mercados se tornaram mais competitivos, principalmente a partir dos anos 1980, observou-se um crescimento nas atividades de pesquisa acadêmica na área de estratégia empresarial, que, em geral, visavam compreender como empresas podem orientar suas condutas com vistas à obtenção de uma vantagem competitiva sustentável. Mesmo para organizações sem fins lucrativos, uma visão estratégica passou a ser considerada essencial para orientar todas as suas atividades de forma coerente e possibilitar que seus recursos sejam adquiridos e alocados de forma a otimizar a sua performance.

Ao longo deste período, a estratégia empresarial tem sido examinada por meio de diferentes modelos conceituais. Para a escola do posicionamento, a definição de estratégia baseia-se na análise da estrutura de uma indústria, em como as forças compet itivas nela se manifestam. Outra abordagem, a visão baseada em recursos (RBV), prioriza a análise dos recursos que a empresa gerencia e como pode desenvolvê-los para diferenciar-se de seus competidores eter, assim, uma vantagem compet itiva sustentável.

A contribuição destas duas escolas é, sem dúvida, muito expressiva. No entanto, foram criticadas por privilegiarem um ou outro aspecto do problema: a estrutura da indústria ou os recursos gerenciados. Em conseqüência, surgiram abordagens que propuseram uma visão mais integrativa para o problema. Nesse sentido, deve-se citar o modelo de coopetição, elaborado em trabalhos de Brandenburger e Nalebuff (1997). Estes autores definem o conceito de rede de valor de uma empresa como uma composição formada não só por seus competidores, fornecedores e clientes, mas, também, por seus complementadores, ressaltando-se que uma empresa pode ocupar simultaneamente mais de um papel em uma rede. Pode ser, por exemplo, ao mesmo tempo, complementadora e competidora. Ritala (2007) propõe que toda cooperação entre empresas pode ser vista como uma combinação complexa de forças cooperativas e competitivas, e define que coopetição é uma cooperação entre empresas que competem entre si, sendo um caso especial de cooperação.

Especial at enção passou a ser dada às alianças estratégicas entre empresas. Estas, quando estabelecem múltiplas alianças, podem formar redes de relacionamento estratégico, laços duradouros e com significância para as suas estratégias (GULATI, NOHRIA; ZAHEER, 2000). Nesse cenário, Gomes-Casseres (1994) propõe que a competição não seja mais vista como o enfrentamento entre empresas em uma determinada indústria, mas, sim, como a competição entre diversos grupos ou redes estratégicas denominadas de "constelações”. Dyer e Singh (1998) afirmam que empresas podem obter um desempenho superior, gerando o que chamam de "renda relacional”, adotando estratégias baseadas em análises relacionais, ou seja, pertinentes aos relacionamentos estabelecidos pelas empresas. Segundo os autores, estas estratégias podem, eventualmente, ser bem diferentes daquelas que seriam elaboradas com base exclusivamente nos conceitos das demais abordagens.

Uma característica das redes de relacionamento estratégico consiste em que elas tomem possíveis trocas de forma mais vantajosa do que se cada uma das empresas envolvidas fosse buscar atender à sua necessidade específica no mercado. No entanto, esta rede estratégica estabelecida pode, em determinadas circunstâncias, deixar de ser vantajosa para todas as partes. Uma empresa pode, por exemplo, se ver impossibilitada de fazer negócios com outras empresas que não façam parte da sua rede. Outro exemplo são situações em que o recurso que uma empresa obtém de outra empresa parceira, considerado estratégico em um dado contexto, deixa de ser adequado em uma nova conjuntura. A empresa encontra dificuldades na adaptação de sua estratégia à nova situação, em função razão do próprio relacionamento outrora visto positivamente. Ou seja, ela estaria aprisionada na rede ou no relacionamento, em uma situação chamada de lock-in.

O objetivo deste artigo é compartilhar os principais resultados de um estudo de caso de uma empresa prestadora de serviços de tecnologia da informação (TI) que, por vários anos, manteve um relacionamento estratégico com um fornecedor e, em virtude das mudanças no cenário tecnológico, traçou uma nova orientação estratégica. A nova estratégia, no entanto, teve a sua efetiva implementação dificultada, em parte, pelas próprias consequiências do longo relacionamento anterior, que criou uma situação de lock-in.

A relevância deste estudo deve-se a dois aspectos principais. Primeiro, ao pesquisar sobre um caso em que o lock-in do relacionamento impacta na adequação da estratégia de uma empresa, contribui-se para o 
conhecimento de um aspecto - pouco pesquisado - da atuação em alianças e redes estratégicas. Segundo, os fatos descritos e sua análise seriam úteis para orientar a ação de administradores envolvidos na administração de relacionamentos inter-organizacionais que apresentam potenciais lock-in e suas conseqüências negativas.

O artigo está estruturado em seis partes, sendo esta introdução a primeira. Na segunda e na terceira, explicamse o referencialteórico e a metodologia. Da pesquisa realizada, na quarta parte,

apresentam-se os resultados do estudo de caso. Em seguida, com o auxílio do referencial teórico e à luz das limitações dos métodos adotados, os principais resultados são discutidos e consolidados. Na última parte, avaliam-se as contribuições da pesquisa, bem como são feitas recomendações para futuras pesquisas, com destaque para algumas lições que o estudo trouxe aos administradores.

\section{Alianças e o Lock-in}

O acirramento do ambiente competitivo estimulou empresas a estabelecerem alianças estratégicas de forma a obter recursos inexistentes internamente ou que, embora passíveis de serem desenvolvidos, seriam mais vantajosos em aquisição por meio de alianças - definidas aqui como arranjos voluntários entre firmas envolvendo troca, compartilhamento ou co-desenvolvimento de produtos, tecnologias ou serviços (GULATI, 1988). As redes estratégicas são consideradas conjuntos de relacionamentos de uma empresa, horizontais e verticais, com outras organizações (GULAT I et al., 2000).

Se as alianças e as redes oferecem recursos utilizáveis na elaboração de suas estratégias, sendo em muitos casos fontes de vantagem competitiva sustentável, há situações em que elas constituem-se em fraqueza para a empresa (GULATI et al., 2000; MACEDO-SOARES, 2002). Isto acontece quando a estrutura da rede da empresa pode prendê-la a uma situação indesejável, causando o lock-in (VILLAS e MACEDO-SOARES, 2007). Por exemplo, no relacionamento entre fornecedor e comprador, o produto fornecido contribuiria para o sucesso da empresa compradora, motivando-a a estabelecer o relacionamento mesmo sobrisco de que no futuro o custo para a mudança seja alto. Tal custo passa a se constituir numa fraqueza da empresa. Segundo Gulati et. al. (2000), este seria o "dark side" das alianças e redes. Mesmo relacionamentos que por muitos anos foram adequados para ambos os parceiros, em conseqüência de mudanças tecnológicas, desenvolvimento do mercado e escolhas estratégicas, deixam de o ser para uma das partes (PARKHE, 1998). Afuah (2000) chama a at enção para o fato de que as mudanças tecnológicas não afetam apenas a empresa focal, ressaltando que a obsolescência de um produto ocorreria em um ponto de sua rede de valor, ou seja, fornecedores, clientes ou complementadores. Qualquer que seja o caso, esta obsolescência afetaria o desempenho não só de uma empresa, mas eventualmente de muitas outras pertencentes à rede específica.

Cabe notar que o conceito de lock-in nem sempre se reveste de conotação pejorativa, principalmente quando se examina a empresa focal como fornecedora de produtos ou serviços. Hax e Wilde II (1999) elaboraram um modelo que contempla três estratégias competitivas: a busca pelo melhor produto, seja por baixo custo ou por diferenciação; a busca por melhores soluções para os consumidores, reduzindo seus custos ou aumentando seus lucros; a busca pelo lock-in do cliente, o qual pode ser alcançado onde existam lock-in de produtos complementadores, lock-out de competidores ou, ainda, padrões proprietários. A análise destes autores foi realizada do ponto de vista de empresas que procuram amarrar seus clientes ou impedir a entrada de competidores, obtendo assim uma vantagem competitiva sustentável. O lock-out de competidores ocorre quando seus clientes têm dificuldades de buscar uma altemativa. Quatro forças contribuem para isso: restrições nos canais de distribuição, o poder da marca, o constante lançamento de novos produtos e as patentes. Para a constituição lock-in, Hax e Wilde II citam produtos com projeto superior, a criação de custos de mudança para os clientes por meio do oferecimento de características únicas no produto e ativos que complementem o produto principal. Existem produtos que são, de fato, um padrão de mercado e propriedade de uma ou poucas empresas. Demais empresas que queiram lançar produtos complementares devem fazer investimentos para adaptá-los ao padrão em vigor. O padrão Wintel é um caso que tem beneficiado amplamente as empresas Microsoft e Intel. 
Greenstein (1995) investigou o fenômeno do lock-in em empresas usuárias de mainframes nos Estados Unidos. Devido à dificuldade de obter dados na iniciativa privada, limitou sua pesquisa ao uso de computadores por agências do governo federal. Existe inter-relacionamento técnico entre produtos quando a compra de um novo terá maior valor, porque os investimentos realizados anteriormente em outros produtos ainda podem ser aproveitados. Esta era uma situação pouco freqüente na troca de fomecedores de mainframe e inexistente na troca de equipamentos mainframes para sistemas computacionais de plataforma aberta. Neste caso, praticamente todo o investimento em sistemas de informações da plataforma anterior é perdido. Este interrelacionamento entre os produtos causa um alto custo de mudança, que pode ainda ser acrescido por fatores como treinamento, operação em dois ambientes durante a transição e interrupção nas operações em razão da instalação do novo sistema. Neste artigo adota-se o conceito de que existe lock-in quando os custos de mudança são elevados a ponto de dificultar a implantação da estratégia mais adequada à empresa, considerando-se o novo ambiente e seus recursos.

Parte-se do pressuposto de que as dificuldades advindas do lock-in relacionam-se à falta de adequação da estratégia empresarial ao contexto em que ela atua e aos seus recursos. Ou seja, a adequação estratégica pode ser comprometida se os custos para as mudanças est ratégicas forem elevados.

O caso tratado neste artigo refere-se a uma situação de lock-in na área de TI. Foi utilizado o modelo de Henderson e Venkatraman (1999) para analisar o alinhamento entre a estratégia de TI e a estratégia de negócios das empresas. Para que haja alinhamento, a estratégia de negócio, a estratégia de TI, a infra-estrutura e os processos organizacionais, bem como a infra-estrutura e processos de TI devem estar consistentes. Este alinhamento pode ocorrer em uma das quatro perspectivas definidas. Na primeira, chamada de execução da estratégia, a estratégia de negócio é a força motriz que determina a infra-estrutura da organização e a infraestrutura de TI. A segunda perspectiva, chamada de perspectiva de transformação, também parte da estratégia de negócio para a estratégia de TI e para a infra-estrutura de TI, diferenciando-se da primeira por não existirem restrições impostas pela infra-estrut ura organizacional. A terceira perspectiva, de potencial competitivo da TI, busca o alinhamento com a TI influenciando a estratégia de negócios e conseqüentemente a infra-estrutura organizacional. Na quarta perspectiva, a estratégia de TI está voltada para o nível de serviço a ser oferecidb, influenciando na infra-estrutura de TI para atender a estrutura e processos organizacionais. Neste trabalho parte-se do pressuposto de que existe adequação estratégica quando há alinhamento entre os objetivos estratégicos dos parceiros; e entre os fat ores organizacionais, tecnológicos e macro-ambientais e a estratégia das empresas envolvidas. Alinhamento é entendido como coerência e consistência.

\section{Metodologia}

Adotou-se o método de estudo de caso, considerado apropriado na medida em que foi importante investigar o fenômeno de lock-in dentro do seu contexto real, em que as fronteiras entre ele e seu contexto não são claramente evidentes (EISENHARDT, 1989; YIN, 2003). Ademais, conforme Halinen e Tornroos (2005), o estudo de caso tem-se apresentado particularmente adequado a pesquisas sobre redes de relacionamentos.

De acordo com a estratégia de triangulação de métodos, os dados foram levantados pelos seguintes meios distintos: investigação documental, levantamento de percepções com o auxílio de entrevistas e observação participante. Relatórios públicos e informações disponíveis no site da empresa foram os documentos utilizados. Realizaram-se entrevistas do tipo não estruturada com um ex-diretor, o coordenador de planejamento e quatro gerentes de nível de departamento e divisão que trabalham na diretoria responsável pelo desenvolvimento dos sistemas na empresa. Foram ouvidos representantes de quatro dos cinco departamentos da referida diretoria. Esta escolha motivou-se por se trat ar de área-chave da organização para a mudança, já que nela se desenvolvem os produtos que substituirão os atuais sistemas do mainframe. Ao longo dos anos, um dos aut ores deste artigo exerceu diversos cargos de gerência na organização e pôde, portanto, contribuir para a pesquisa com observação participante. A utilização de diferentes meios e fontes reduziram o risco de que a pesqui sa tivesse algum viés caso fosse utilizada uma única fonte. 
Devido à natureza do problema investigado, realizou-se um estudo longitudinal na empresa-foco. Foram levantados documentos relativos às décadas de 1990 e 2000, período a partir do qual surgiu a necessidade de realizar mudanças estratégicas, na empresa, relativas à tecnologia utilizada. As entrevistas foram realizadas nos meses de maio e junho de 2007.

\section{Resultados da Pesquisa}

\section{A Dataprev e seu contexto}

O objetivo desta seção é descrever as principais características da empresa, identificar o momento em que o relacionamento estratégico com um fornecedor deixou de ser de seu interesse, demonstrar a dificuldade que a organização atravessa para sair da situação de lock-in e efetuar as mudanças necessárias ao estabelecimento de uma adequação entre sua estratégia e o seu contexto.

A Empresa de Tecnologia da Informação da Previdência Social (DATAPREV) foi fundada em 1974, como uma empresa pública de direito privado, com capital controlado pelo Ministério da Previdência Social (MPS) e pelo Instituto Nacional do Seguro Social (INSS), que controlam 51\% e 49\% do capital, respectivamente. Tem como principais clientes o próprio INSS e MPS, mas presta serviços também para o Ministério do Trabalho e Emprego (MTE), Ministério do Desenvolvimento Social (MDS), rede bancária, entre outros. Quanto ao escopo de seus serviços, a empresa realiza conceituação e desenvolvimento de sistemas, processamento de dados, serviços de redes de telecomunicações, consultorias e treinamentos. Atua em todo o Brasil, com sede em Brasília e escritórios em praticamente todos os estados.

A missão e a visão declaradas para o período, conforme expresso nos relatórios de gestão, refletem uma mudança na estratégia da empresa ocorrida nos anos deste estudo. Até o ano de 2003, a missão era explicitamente prestar serviços à Previdência Social, ou seja: "Dotar a Previdência Social de soluções em tecnologia da informação, com segurança, disponibilidade e utilidade, a preços competitivos”. (DAT APREV, 2003, p. 9)

Em 2004 nota-se uma mudança que amplia a área de atuação da empresa, em que se faz referência explícita à área de atuação do Ministério do Trabalho e Emprego. A nova declaração de missão passou a ser:

Atuar integradamente com outras instituições públicas para o êxito das ações de governo, no âmbito da seguridade social e do trabalho, por meio de soluções sustentáveis em tecnologia da informação, com o fortalecimento do compromisso entre trabalhadores e empresa, agindo de forma a preservar o interesse público. (DATAPREV, 2004, p. 5)

No relatório de gestão de 2005, adota-se uma abordagem mais ampla que reflete não apenas a existência de clientes fora do âmbito do MPS, mas também uma orientação pela busca de novos clientes, principalmente na área social do governo. A nova declaração de missão correspondente a esta estratégia é: “Atuar int egradamente com outras instituições públicas para o êxito das ações de governo, por meio de soluções em tecnologia de informação e comunicação, de forma a preservar o interesse público" (DATAP REV, 2005, p. 5).

Em síntese, as mudanças nas declarações refletem uma intenção da empresa em procurar a expansão de mercados. As declarações de visão também sofreram modificações que não representaram, contudo, uma mudança tão significativa quando as ocorridas na declaração de missão. A visão de 2006 passou a ser: “[...] uma empresa pública de soluções em Tecnologia da Informação e da Comunicação reconhecida por sua excelência na gestão, pelos serviços prestados e pela contribuição para a sociedade” (DAT APREV, 2006, p. 5).

A indústria de informática foi, por longo tempo, dominada pelos computadores de grande porte com arquit et ura proprietária, hoje chamados de mainframe, em que cada fabricante lançava seus produtos com características próprias e sistemas operacionais incompatíveis entre si. Esta incompatibilidade provoca um grande custo de mudança à empresa que pretenda trocar de fomecedor. Para o desenvolvimento de seus serviços, a Dataprev, desde sua fundação, fez uma escolha estratégica ao adotar os equipamentos de grande porte da empresa Unisys, 
antiga Burroughs. Na época, os mainframes eram a única opção para suportar o volume de processamento efetuado, cabendo apenas a definição quanto à escolha do formecedor. As conseqüências desta escolha não ficaram restritas apenas à função de processamento de dados, pois provocaram também grande impacto no processo de desenvolvimento de sistemas e nas tecnologias utilizadas. Também tem sido grande a influência sobre as habilidades requeridas dos técnicos da empresa e, mais particularmente, dos analistas de sistemas e programadores. Dificilmente, hoje, um analista de sistema sente-se motivado a trabalhar neste ambiente, em razão de sua arquitetura proprietária e de sua pouca aceitação no mercado.

Entretanto, deve-se ressaltar que o ambiente tecnológico de computadores de grande porte Unisys, ainda em 2005, foi avaliado positivamente pelo Gartner Consulting, que o considerava atrativo para as empresas que já tinham investimentos em sistemas nesta plataforma. O Gartner desencoraja a entrada, neste ambiente, de empresas que com ele não estão comprometidas em conseqüência de sua pequena participação no mercado e do pequeno conjunto de aplicações disponíveis, bem como pela dificuldade em contrat ar técnicos com treinamento e motivados a trabalhar nesta plat aforma tecnológica (GART NER, 2006).

A estratégia da Unisys, no período coberto pela pesquisa, pode ser dividida em quatro grandes fases (LAVIE; SINGH, 2007). A primeira diz respeito à época dos mainframes e vai de 1970 a 1990. Na segunda dá-se a mudança para sistemas abertos, correspondendo à primeira metade dos anos 1990. A terceira ocorre no período de 1995 a 1999 e refere-se a uma reestrut uração que dividiu a empresa em três áreas de negócios: serviços de informação, sist emas de computadores e serviços para clientes globais. Na quarta fase, a partir do ano 2000, a empresa procurou posicionar-se como uma organização de serviços de tecnologia de informação. Disto se deduz que o relacionamento da Dataprev com a Unisys inicia-se na primeira fase estratégica citada.

Pelo menos até 1998, a utilização dos equipamentos de grande porte Unisys não foi questionada institucionalmente. Nesta época estava em vigor a definição de que os sistemas corporativos deveriam ser hospedados no ambiente de mainframe Unisys. Novos sistemas corporativos poderiam ser desenvolvidos tanto para o mainframe quanto para ambientes computacionais abertos. Os sistemas de abrangência departamental deveriam ser construídos nos sistemas abertos.

\section{O lock-in da tecnologia adotada}

Entre os documentos analisados na pesquisa, identificou-se o relatório de gestão de 2000 como a primeira vez em que se expressou como objetivo corporativo a necessidade de conversão dos sistemas para arquiteturas tecnológicas abertas. O objetivo estratégico foi assim formulado: “[...] adotar arquiteturas não proprietárias, sistemas abertos e protocolos universais” (DAT APREV, 2001, p. 34). É a partir deste momento, port anto, que se identifica a existência do lock-in e de suas conseqüências para a empresa pesquisada. No ano seguinte, o mesmo objetivo estratégico aparece repetido integralmente. № relatório de 2001, observa-se a seguinte afirmação: “A migração de plataformas é um tema que envolve alta complexidade, riscos significativos e grandes investimentos. Deve estar intrinsecamente associada a estratégias de desenvolvimento do negócio e tendências tecnológicas” (DATAPREV, 2001, p. 15).

Conclui-se, desta assertiva, que os administradores da empresa estavam conscientes da barreira à mudança que representavam os altos investimentos necessários para a implantação da nova estratégia. Além disso, em virtude do esforço necessário, a estratégia de negócio referida estava intimamente ligada à de negócios do INSS, apontando para a necessidade de alinhamento de ambas. A migração da plataforma computacional requereria um esforço da Dataprev possível apenas se as duas instituições estivessem de acordo com a orientação, pois recursos que estariam envolvidos em processos de melhorias adaptativas dos sistemas existentes ficariam comprometidos com o novo projeto. É interessante notar que o mesmo objetivo estratégico foi relacionado no relatório de gestão de 2002, no entanto, dos projetos em desenvolvimento destacados não const ava nenhum relativo à migração do mainframes Unisys (DAT APREV, 2003).

Nesta época surgiu outro fator para a questão da migração da plataforma e a conseqüente dissolução de um relacionamento estratégico de muitos anos: a questão dos preços. Por setratar de uma arquitetura proprietária, o Tribunal de Contas da União (TCU) entendeu que os preços praticados pela Unisys não eram compatíveis com 
o mercado. Além disso, a contratação de outro fomecedor através de licitações públicas ficava inviabilizada, considerando-se que a Unisys era a única fornecedora das tecnologias utilizadas. Sendo assim, o TCU determinou que, em um prazo de cento e oitenta dias, a Dataprev elaborasse um plano de migração dos sistemas e das bases de dados para a plataforma aberta (TCU, 2002). Investigar se os preços eram ou não apropriados está fora do escopo deste artigo. No entanto, a sinalização deste problema é relevante para demonstrar que a decisão estratégica da mudança extrapola a lógica intema da Dataprev e envolve outras esferas de govemo, reforçando a sua importância estratégica para a empresa.

Nos relatórios dos anos de 2003 e 2004, percebe-se o desaparecimento do objetivo estratégico anteriormente citado, que já se repetia há três anos. Pode-se admitir que ele tenha sido substituído por outro, com formulação mais genérica: "Desenvolver política para definição, aquisição e atualização permanente de tecnologias adequadas às necessidades dos negócios e dos clientes” (DAT APREV, 2003, p. 16). Se, por um lado, nesta época, a orient ação para a adoção de soluções de sistemas em plataformas abertas era prat icamente consensual na empresa, por outro, a formulação genérica citada não era enfática na conversão dos sistemas com plataformas do mainframe, ainda usadas nos principais sistemas da empresa.

O tema da migração dos sistemas volta a ser trat ado de forma explícita no relatório de gestão de 2005, no qual está consignado o objetivo "Eliminar a dependência tecnológica”, bem como a ação "Modernizar e migrar os sistemas de informação para plataforma aberta” (DATAPREV, 2005). Destaca-se, também, neste relatório de gestão de 2005, a presença do Plano de Modernização Tecnológica (PMT), um instrumento que possibilite não apenas a modemização da organização, mas também dos próprios processos do INSS. Mais uma vez, por modernização tecnológica ent ende-se a adoção de tecnologias abertas. Os processos do INSS foram redefinidos pelo projeto "Novo Modelo de Gestão” (NMG), de responsabilidade do INSS, com o objetivo de redesenhar os processos organizacionais, cuja implementação é fortemente dependente do desenvolvimento de novos sistemas de informações ou de alterações dos que estão em funcionamento na plataforma tecnológica dos mainframes.

O PMT é composto pelo plano de sistemas, plano de infra-estrut ura, plano de capacitação e retenção e plano de investimento. O plano de capacitação e retenção decorre da necessidade de desenvolver os recursos humanos para trabalhar no novo ambiente tecnológico, uma vez que as competências intemas são fundamentalmente voltadas para a arquitetura proprietária em uso. O Plano de Modernização Tecnológica veio substituir o Comitê de Modemização Tecnológica (CGMT), ariado em 2004 com o intuito de promover a migração dos sistemas do ambiente Unisys para a plataforma aberta.

O relatório de 2006 mostra-se consistente em relação ao de 2005. Nele está descrito o projeto do PMT em um nível mais detalhado, incluindo um cronograma para as atividades, que previa uma duração total de cinco anos. A estrutura organizacional da diretoria de desenvolvimento de sistemas foi alterada ao final de 2005, com o objetivo de facilitar o processo de desenvolvimento com o uso das novas metodologias que a empresa se propôs a praticar.

Avaliava-se que existiam problemas referentes aos recursos humanos que deviam ser mobilizados para que o projeto fosse bem sucedido: a) falta de técnicos em quantidade suficiente para simult aneamente desenvolver os novos sistemas e sustentar os sistemas existentes até que viessem a ser substituídos; b) inadequação dos conhecimentos dos analistas de sistemas em relação às novas tecnologias escolhidas. Para ter acesso às competências técnicas necessárias à tarefa de migração de plataforma, a empresa e o INSS decidiram-se, em 2005, pela contratação de empresas de consultoria para o desenvolvimento dos novos sistemas, em parte ou integralmente. Esta contratação, por dois anos, foi efetuada através de uma licitação cujo resultado teve sua conclusão apenas em setembro de 2006.

\section{A percepção dos gerentes da empresa}

As entrevistas com gerentes, realizadas em junho de 2007, permitiram identificar, segundo suas percepções, as principais razões para que um objetivo estratégico seja renovado anualmente, por cerca de oito anos, sem que ele seja de fato implementado na empresa, deixando-a presa (locked-in) ao seu antigo relacionamento, mesmo 
quando, manifestadamente, não é mais de seu interesse. Deve-se ressaltar, no entanto, que a natureza da mudança proposta não foi consensual entre todos os gerentes entrevistados, tendo havido opinião minoritária pela manutenção do tipo de relacionamento existente. O seguinte extrato de uma das entrevistas realizadas reflete esta percepção:

Acho extremamente ousado pretender abrir mão completamente dos mainframes, quando se trata de processar os volumes de informações que processamos, com significativo grau de complexidade. Basta olharmos para qualquer outra organização semelhante à nossa para vermos que todas, sem exceção, apóiam-se em mainframes, ainda que se utilizem da plataforma baixa para seus front-ends.

A principal razão apontada para a falta de implementação da estratégia foi a falta de alinhamento entre a Dataprev e seus clientes MPS e INSS. Um projeto desta envergadura só seria viável se houvesse um entendimento entre as partes interessadas, o que não teria ocorrido em boa parte do período. A seguir apresentamos um exemplo extraído das entrevistas:

As tentativas anteriores de implantação de projetos de modemização tecnológica na Previdência Social não lograram êxito devido, principalmente, às questões envolvendo processos de comando $e$ controle político da TIC entre 2000 e 2004. A falta de alinhamento das ações relacionadas à TIC entre MPS, INSS e Dataprev não proporcionou o ambiente de gestão e os recursos necessários à Dataprev para que esta desse início, de fato, à grande transformação tecnológica da Previdência Social.

A relação entre a falta de alinhamento com o INSS e a falta de recursos para os investimentos foi seguidamente citada como motivo para a ausência de investimentos concretos no projeto.

Outro fator importante que impactou negativamente a meta foi a falta de investimentos. Apesar de o objetivo fazer parte dos relatórios de gestão, o repasse de recursos para que a empresa fizesse os investimentos necessários para atingir esta meta não aconteceu. A mola propulsora para esta mudança som ente foi disparada quando o NMG procurou a Dataprev para participar do detalham ento dos processos do novo modelo. Com isto, apareceram também os recursos para viabilizar a migração tecnológica.

Um planejamento inadequado para os projetos também foi apontado, conforme um dos relatos: "Propor metas fora da realidade e da capacidade da Empresa foi uma das razões do não atingimento dos compromissos assumidos, alie a isto a falta de uma estrat égia de implantação para vários anos, não para o momento".

Outros fatores citadbs foram: o número de vezes em que a direção da empresa foi alterada gerando uma excessiva descontinuidade administrativa; a complexidade técnica do empreendimento; e a falta de um processo de capacitação do corpo técnico e gerencial.

\section{Discussão dos Resultados}

Os resultados da pesquisa demonstram que por um longo período o relacionamento da Dataprev com a Unisys permitiu que fossem gerados os produtos necessários para a Previdência Social. No entanto, a evolução do mercado de tecnologia na década de 1990 pode não ter sido abordada adequadamente pela empresa focal. As informações levantadas sugerem que uma das empresas envolvidas no relacionamento, a Unisys, procurou se adaptar às mudanças tecnológicas em curso, conforme ficou demonstrado nas quatro fases da estratégia desta empresa. Já para a empresa focal, para a qual o relacionamento pode ser considerado estratégico, a mudança veio muito lentamente. Enquanto no início da década de 1990, a Unisys já procurava se reposicionar para enfrentar as mudanças tecnológicas; apenas em 2000, a Dataprev formula explicitamente, no seu relatório de gestão, o objetivo de que os sistemas corporat ivos estejam em plat aforma aberta. 
Analisando sob a ótica dos conceitos da rede de valor, tal qual definida pelo conceito de coopetição, as duas empresas são, ao mesmo tempo, complementadoras e competidoras. Complementadoras porque o valor da Dataprev para os seus clientes é maior do que sem a tecnologia adquirida da Unisys. São competidoras principalmente após a Unisys ter adquirido a empresa Datamec no processo de privatização. Esta aquisição trouxe o Ministério do Trabalho e Emprego para sua carteira de clientes no negócio de desenvolvimento de sistemas.

O contrato com a Unisys durante muitos anos propiciou à Dat aprev recursos necessários para o cumprimento de seus objetivos. Não se tratava apenas de computadores de grande porte, mas também de consultoria e absorção de conhecimento. As novas tecnologias disponíveis, no entanto, geraram novas possibilidades as quais foram vislumbradas pela Dat aprev como mais adequadas aos seus interesses.

Após a consignação da intenção de mudança estratégica em 2000, durante pelo menos os dois anos seguintes, não foram iniciados projetos devidamente apoiados com recursos que permitissem à empresa produzir os novos sistemas em plataforma aberta. Esta morosidade na ação acabou por causar um ciclo vicioso: a empresa deixou de desenvolver os recursos necessários à criação de produtos que iriam ser requeridos poucos anos após. Os profissionais de informática da empresa estavam alocados principalmente na sustentação dos produtos da plataforma do mainframe; conseqüentemente, deixaram de desenvolver as habilidades para trabalhar no novo ambiente. À medida que o tempo passava, esta situação reforçava o lock-in, já que se tomava cada vez maior a diferença entre os dois ambientes e os investimentos necessários à mudança. Pode-se afirmar, portanto, que os recursos obtidos na aliança gradualmente deixaram de ser adequados ao novo contexto e que, apesar da int enção de mudança estrat égica manifestada, os altos custos envolvidos reforçavam o lock-in estratégico.

As circunstâncias que envolvem a empresa em foco levaram a que o alinhamento da TI fosse analisado em relação ao INSS, seu cliente principal e, ao mesmo tempo, o proprietário da empresa. Apenas quando foi estabelecido o alinhamento estratégico entre as duas organizações, no início de 2006, é que se pôde constatar um maior progresso nos projetos de mudança. Ficou claro que a falta de alinhamento entre os objetivos estratégicos da Dataprev e os do INSS inibiram a realização dos investimentos necessários para que os projetos pudessem ser executados de forma continuada. $\mathrm{O}$ alinhamento em questão remete à primeira perspectiva apontada no modelo de Henderson e Venkatraman (1999), ou seja, diz respeito à estratégia do INSS no sentido de implantar um novo modelo de gestão que seja suportado por uma nova infra-estrutura organizacional do INSS e por uma nova estrut ura de TI provida pela Dat aprev.

Definida a forma de alinhamento, resta a complexidade dos projetos que irão construir os produtos para substituir a antiga plataforma proprietária. Considerando o cronograma elaborado, a empresa renovou, no primeiro semestre de 2007, o contrato com a Unisys por mais três anos, embora esteja previsto que neste período equipamentos possam ser devolvidos à fornecedora.

\section{Conclusão}

Esta pesquisa permitiu observar os problemas decorrentes da dificuldade de se desfazer de um relacionamento estratégico em situação de lock-in em uma empresa prestadora de serviços de tecnologia da informação.

A partir do ano 2000, a empresa pesquisada definiu o objetivo de mudar sua plataforma tecnológica e isto, necessariamente, significava romper o relacionamento estratégico de tantos anos com a Unisys. No entanto, sete anos após a definição deste objetivo, reiterado a cada ano, a situação na prática não mudou: a empresa mantinha os seus principais sistemas, no ambiente de computadores e software básico, fornecidos pela Unisys.

Ficou evidente no estudo que o lock-in foi conseqüência dos custos de mudança gerados por um relacionamento que perdeu seu alinhamento estratégico. A implantação do novo objetivo estratégico exigiria investimentos para a aquisição de novos equipamentos, treinamento de pessoal e desenvolvimento de novos sistemas. A pesquisa demonstrou que a falta de alinhamento entre as estratégias da Dataprev e do INSS inviabilizou o empreendimento no período analisado. A consultoria que fomecerá os recursos para o processo 
de conversão foi contratada por um prazo de dois anos; desse modo, éprovável que, pelo menos, até o final de 2008, a decisão estratégica de 2000 ainda não esteja plenamente efet ivada.

Os resultados da pesquisa demonstraram, por meio de um estudo de caso, como o lock-in pode, de fato, retardar ou impedir reorientações estratégicas em organizações. Também trouxeram subsídios que podem ser úteis a administradores em seus processos decisórios no sentido de avaliar a conveniência do engajamento em determinados relacionamentos que potencialmente amarrariam a empresa ao seu fornecedor. Evidenciou-se a relevância de que sejam detectados prontamente aqueles relacionamentos que, devido às mudanças que envolvem a empresa, tenham deixado de ser adequados estrat egicamente, pois os custos para a mudança podem ser progressivamente maiores à medida que a situação se perpetua. Conseqüentemente, as empresas devem estabelecer processos de avaliação periódica de seus relacionamentos, analisando seu alinhamento com a estratégia, a qual deve estar adequada às mudanças do ambiente, da tecnologia e dos recursos organizacionais.

Esta pesquisa teve seu escopo restrito ao caso de uma única empresa. Embora lições tenham sido extraídas, pouco se sabe sobre a ocorrência de fenômenos similares em outras empresas que tenham encerrado parcerias nos mais diversos setores da economia. Esta lacuna poderia ser preenchida com uma pesquisa que investigasse, no contexto brasileiro, o término de alianças estratégicas, identificando suas causas e até que ponto o lock-in causou problemas para alguma das partes envolvidas no processo. 


\section{Referências Bibliográficas}

AFUAH, Allan. How Much do Your Co-opetitors' Capabilities Matters in the Face of Technological Change? Strategic Management J ournal, v. 21, n. 3, p. 387-404, 2000.

BRANDENBURGER, A. M.; NALE BUFF, B. J. Coopetition. Doubleday : N ew York, 1997.

CEPIK, M.A.C.; EISENBERG, J.M.; EKLUND, M.S. Desenhos institucionais em informática pública: estudo comparativo em quatro cidades brasileiras. Informática Pública, Belo Horizonte - MG, v. 3, n. 2, p.47-72, 2001.

DATAPREV. Relatório de Gestão 2000. 2001.

DATAPREV. Relatório de Gestão 2001. 2002.

DATAPREV. Relatório de Gestão 2002. 2003.

DATAPREV. Relatório de Gestão 2003. 2004.

DATAPREV. Relatório de Gestão 2004. 2005.

DATAPREV. Relatório de Gestão 2005. 2006.

DATAPREV. Relatório de Gestão 2006. 2007.

DYER, J., SINGH, H. The relational view: cooperative strategy and sources of interorganizational competitive advantage. TheA cademy of Management Review, v. 23, n. 4, p. 660-679, 1998.

EISENHARDT, K. M. Building theories from case study research. The Academy of Management Review, v. 14, n. 4, p. 532$550,1989$.

GARTNER. Vendor Rating U pdate: U nisy s refocuses for profit Gartner Group, Mar., 2006.

GOMES-CASSERES, B. Group versus group: how alliance netw orks compete. Harvard Business Rev iew , v. 72, n. 4, p. 62-74, 1994.

GREENSTEIN, S. M. Lodk-in and the costs of sw itching mainframe computer vendors in the US Federal Government in the 1970s. IEEE A nnals of the History of Computing, v. 17, n. 3, p. 58-66, 1995.

GU LATI, R. Alliances and Network. Strategic Management J ournal, v. 19, n. 4, p. 293-317, 1998.

GU LATI, R., NOHRIA, N., ZAHEER, A. StrategicN etworks. Strategic Management J ournal, v. 21, n. 3, p. 203-215, 2000.

HA UNEN, A.; TORNROOS, J. Using Case methods in the study of contemporary business networks. J ournal of Business Research, v. 58, n. 9, p. 1285-1297, 2005.

HAX, A. C.; WI DE II , D. L. The Delta Model: adaptive management for a changing world., MIT Sloan Management, v. 40, n. 2, p. 11-28, 1999.

HENDERSON, J. C.; VENKATRAMAN, N. Strategic Alignment: Leveraging Information Technology for Transforming Organizations. I BM Systems Journal, v. 32, n. 1, p. 4-16, 1993.

LAVIE, D.; SINGH, H. The evolution of alliance portfolios: the case of Unisy s. EURAM I nternational Conference, 2007, Paris.

MACEDO-SOARES, T. D.L.V.A. Strategic alliances and netw orks: conceptual tools for strategic assessments. In: Readings book of global business and technology association. GBATA, I nternational Conference, p. 292-305, Roma, 2002.

PARKHE, A. Building trust in international alliances. J ournal of World Business, v. 33, n. 4, p. 417-437, 1998.

RITA LA, P. The Ambiguous Role of Competition in I nterfim Relationships. European Academy of Management C onference, Paris, 2007. 
VILLAS, M., MACEDO-SOARES, T.D.L.V.A. The influence of strategic alliance netw orks on information and communication technology: results of an exploratory empirical study. J ournal of G bbal Business and Technology, v.3, n. 1, 2007.

TCU. Decisão 1459 / 2002-P lenário. 2002.

YIN, R. Case study research: design and methods. Sage Publications, Londres, 2003. 